\title{
Endoscopic Management of Dieulafoy's Lesion
}

\author{
Hye Kyung Jeon and Gwang Ha Kim \\ Department of Internal Medicine, Pusan National University Hospital, Pusan National University School of Medicine, Busan, Korea
}

\begin{abstract}
A Dieulafoy's lesion is a vascular abnormality consisting of a large caliber-persistent tortuous submucosal artery. A small mucosal defect with the eruption of this protruding vessel can cause bleeding. In fact, a Dieulafoy's lesion is a relatively rare but potentially life-threatening condition. It accounts for $1 \%$ to $2 \%$ of cases of acute gastrointestinal bleeding. Although there is no consensus on the treatment of Dieulafoy's lesions; treatment options depend on the mode of presentation, site of the lesion, and available expertise. Endoscopic therapy is usually successful in achieving primary hemostasis, with hemostasis success rates reaching $75 \%$ to $100 \%$. Although various therapeutic endoscopic methods are used to control bleeding in Dieulafoy's lesions, the best method for endoscopic intervention is not clear. Combination endoscopic therapy is known to be superior to monotherapy because of a lower rate of recurrent bleeding. In addition, mechanical therapies including hemostatic clipping and endoscopic band ligation are more effective and successful in controlling bleeding than other endoscopic methods. Advances in endoscopic techniques have reduced mortality in patients with Dieulafoy's lesionfrom $80 \%$ to $8 \%$ - and consequently, the need for surgical intervention has been reduced. Currently, surgical intervention is used for cases that fail therapeutic endoscopic or angiographic interventions.
\end{abstract}

Key Words: Dieulafoy's lesion; Endoscopic treatment; Gastrointestinal tract

\section{INTRODUCTION}

A Dieulafoy's lesion in the gastrointestinal (GI) tract, initially described by the French surgeon Dieulafoy as exulceratio simplex in 1898, is a rare but important cause of GI bleeding. ${ }^{1,2}$ It is defined as a vascular abnormality consisting of a large-caliber, persistent, tortuous submucosal artery. The artery fails to taper as it reaches the mucosa and hence has a diameter of 1 to $5 \mathrm{~mm}$, which is 10-time thicker than the normal size of an artery at that level. ${ }^{3-6}$ Microscopically, the artery protrudes through a small mucosal defect that is typically 2 to $5 \mathrm{~mm}$ long and does not show any other abnormality of the arterial wall. Ulceration is limited to the overlying mucosa, whereas the surrounding mucosa appears histologically normal. ${ }^{5} \mathrm{Up}$ to $6 \%$ of nonvariceal bleeding in the upper GI tract ${ }^{7,8}$ and $1 \%$ to $2 \%$ of all acute GI hemorrhage ${ }^{6,9}$ are caused by a Dieulafoy's lesion. Some-

Received: September 1, 2014 Revised: November 2, 2014

Accepted: November 3, 2014

Correspondence: Gwang Ha Kim

Department of Internal Medicine, Pusan National University Hospital, Pusan National University School of Medicine, 179 Gudeok-ro, Seo-gu, Busan 602739 , Korea

Tel: +81-51-240-7869, Fax: +81-51-244-8180, E-mail: doc0224@pusan.ac.kr

(c) This is an Open Access article distributed under the terms of the Creative Commons Attribution Non-Commercial License (http://creativecommons.org/ licenses/by-nc/3.0) which permits unrestricted non-commercial use, distribution, and reproduction in any medium, provided the original work is properly cited. times, massive bleeding from this lesion can have a fatal clinical outcome unless adequate treatment is promptly initiated ${ }^{10,11}$ and mortality rates (approximately $5 \%$ ) are similar to those of other causes of GI bleeding. ${ }^{12}$

\section{PATHOGENESIS AND ANATOMIC DISTRIBUTION}

Once believed to be acquired and aneurysmal in nature, ${ }^{13}$ pathological reports have failed to associate Dieulafoy's lesion to aneurysms, arteriosclerosis, elastic tissue abnormalities, or signs of vasculitis. ${ }^{1,6,14,15}$ In younger patients, a congenital defect may bring a large submucosal artery in close apposition with the mucosa. ${ }^{9,14,16}$

To date, the exact mechanism that triggers the bleeding is not fully understood. Several mechanisms have been proposed to explain the rupture and subsequent massive hemorrhage. One mechanism focuses mainly on the combined effect of atrophy and ischemia of the mucosa. The pulsation in a thick, large submucosal artery applies pressure to the overlying epithelium and leads to a small erosion and rupture of the vessel towards the lumen. ${ }^{1,6,17}$ Clinically, Dieulafoy's lesion presents with intermittent and painless GI bleeding., ${ }^{4,18}$ Another theory suggests that thrombosis within the artery and subsequent ne- 
crosis of the arterial wall plays a primary role in the ultimate arterial rupture. ${ }^{6,15}$ The absence of a mucosal inflammatory reaction at the site of the arterial rupture indicates that an acidpeptic process is not involved. ${ }^{6}$ For colonic Dieulafoy's lesion, an additional mechanism has been suggested where by solid bowel content can contribute to mucosal stercoral ulceration over an abnormally dilated submucosal arteriole and lead to subsequent rupture and hemorrhage. ${ }^{6}$

The stomach is the most common site for Dieulafoy's lesions. ${ }^{7.16}$ Of these lesions, $80 \%$ to $95 \%$ occur within 6 to $10 \mathrm{~cm}$ of the gastroesophageal junction, generally along the lesser curvature of the stomach. ${ }^{1,6,14}$ Approximately one-third of lesions are extragastric, located most frequently in the duodenum followed by the colon. ${ }^{19}$ They have also been described in the esophagus, jejunum, ileum, rectum, and anal canal. ${ }^{20-23}$

\section{EPIDEMIOLOGY AND CLINICAL PRESENTATION}

Dieulafoy's lesion can occur at any age. The mean age of presentation is in the fifth decade of life, and there appears to be no familial predisposition associated with the lesion. ${ }^{6}$ It is seen twice as frequently in men as in women ${ }^{6}$ and may be more common in patients with co-morbidities such as cardiovascular diseases, chronic renal diseases, hypertension, and diabetes mellitus. ${ }^{414}$ It has also been associated with the use of nonsteroidal anti-inflammatory drugs (NSAIDs), aspirin, and antiplatelet aggregation agents, although the effects of heavy smoking and alcohol consumption are not consistently welldocumented. $3,6,14,24$

The characteristic clinical presentation is sudden onset of painless, massive, recurrent, intermittent hematemesis at times associated with melena, hematochezia, and hypotension. ${ }^{6,25}$
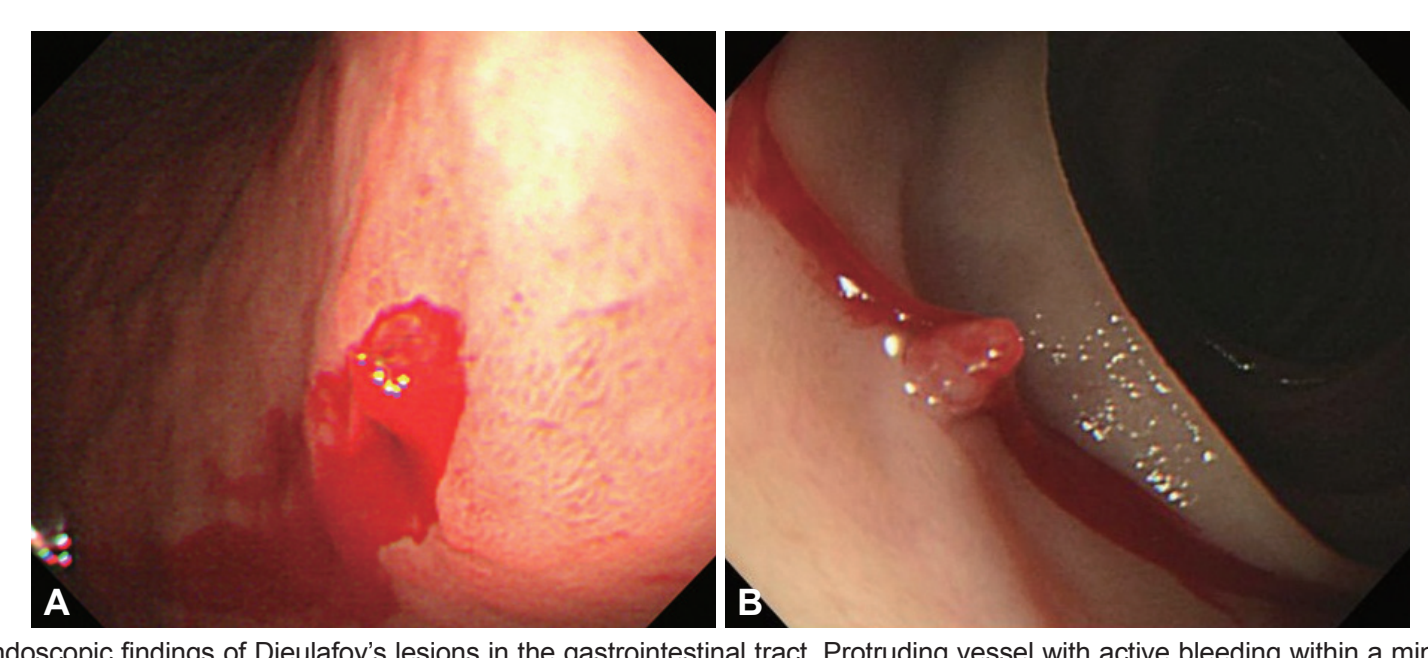

Fig. 1. Endoscopic findings of Dieulafoy's lesions in the gastrointestinal tract. Protruding vessel with active bleeding within a minute mucosal defect and normal surrounding mucosa is visualized in the stomach (A) and jejunum (B).

\section{INVESTIGATIONS OF DIEULAFOY'S LESION}

\section{Endoscopy}

The endoscopic criteria that define a GI Dieulafoy's lesion are the following: ${ }^{7}(1)$ active arterial spurting or micropulsatile streaming from a minute $(<3 \mathrm{~mm})$ mucosal defect or through normal surrounding mucosa; (2) visualization of a protruding vessel with or without active bleeding within a minute mucosal defect or through normal surrounding mucosa; and (3) the appearance of a fresh, densely adherent clot with a narrow point of attachment to a minute mucosal defect or mucosa of normal appearance.

A Dieulafoy's lesion is usually diagnosed using endoscopy (Fig. 1). Diagnosis is most easily performed during or immediately following an episode of bleeding, but the endoscopic diagnosis may be difficult, especially during the first episode, because of the small nature of the lesion, normal appearance of the surrounding mucosa, and intermittent nature of the hemorrhage. Therefore, multiple endoscopies are often necessary for diagnosis. ${ }^{12,20,26}$ Approximately $49 \%$ of these lesions are identified during an initial endoscopic examination; however, $33 \%$ of lesions require more than one endoscopy to correctly identify the source of the bleeding. ${ }^{25}$ Endoscopic ultrasonography (EUS) has also been used to aid endoscopic diagnosis by revealing a tortuous submucosal vessel near the mucosal defect. $^{27,28}$

Push enteroscopy, which is an extension of upper GI endoscopy, allows assessment and direct evaluation of the small intestine with a diagnostic yield of $70 \%$ to $100 \%$ in patients with obscure GI bleeding. ${ }^{29}$ Successful localization of a Dieulafoy's lesion has also been achieved using wireless capsule endoscopy, which has the benefit of being minimally invasive; however, it does not allow therapeutic intervention. ${ }^{29,30}$ Recently, the

sal defect and normal surrounding mucosa is visualized in the stomach (A) and jejunum (B). 
usefulness of double balloon enteroscopy (DBE) or single balloon enteroscopy (SBE) has been suggested for the detection of a Dieulafoy's lesion in the small bowel. In patients who underwent DBE or SBE because of suspected mid-GI bleeding, a Dieulafoy's lesion of the small bowel was identified as the source of bleeding in $3.5 \%$ of patients, and a mean of 1.5 enteroscopy sessions were required to establish diagnosis. ${ }^{21}$

\section{Angiography}

Angiography is useful when endoscopy fails to localize the lesion. There are no specific diagnostic criteria for identifying a Dieulafoy's lesion on angiography, but the diagnosis is suggested on demonstration of a tortuous and ectatic artery. ${ }^{1,6,14}$ The findings during active bleeding include extravasation of contrast from a normal looking blood vessel (Fig. 2).

\section{ENDOSCOPIC TREATMENT OF A DIEULAFOY'S LESION}

There is no consensus on the treatment of a Dieulafoy's lesion. Treatment options are dependent on the mode of presentation, site of the lesion and available expertise. In the years following the first description of this condition, most patients with a bleeding Dieulafoy's lesion were treated surgically. ${ }^{3}$ In 1990, Goldenberg et al. ${ }^{31}$ suggested that, before surgery, the endoscopic treatment of Dieulafoy's lesion should be attempted. With advances in endoscopic techniques, endoscopic therapy has gradually replaced surgery and has emerged as the first option for diagnosing and managing Dieulafoy's lesions. ${ }^{10}$ Endoscopic treatment is safe and highly successful in terms of achieving initial hemostasis and hemostasis success rates reach $75 \%$ to $100 \%$ (Table 1 ). ${ }^{4,7,10-13,18,21,24,32-47}$ With the introduction of DBE and SBE into clinical practice, endoscopic therapy of a small-bowel Dieulafoy's lesion, has also become an attrac- tive option. ${ }^{21,29,48}$

\section{Classification of endoscopic treatment}

Endoscopic hemostatic procedures can be classified into three groups: (1) regional injection: local epinephrine injection and sclerotherapy; (2) thermal: electrocoagulation, heat probe coagulation and argon plasma coagulation (APC); and (3) mechanical: banding and hemostatic clips. ${ }^{1,6,9}$

\section{Regional injection therapy}

Epinephrine is injected (dilution, 1:10,000) to four quadrants with $2.5 \mathrm{~mL}$ initially, with repeated injections until the cessation of bleeding is maintained. ${ }^{35}$ It is widely available, relatively inexpensive, simple and comparatively safe in avoiding damage to the bowel wall. However, there are some limitations to the use of injection therapy as the definitive therapy for bleeding Dieulafoy's lesions. The use of epinephrine alone in the management of a suspected Dieulafoy's lesion is not advocated because of the possibility of rebleeding. ${ }^{34,49}$ Epinephrine preinjection around the lesion before other treatment modalities should only be used to reduce the potential for excessive bleeding during therapy. ${ }^{25}$ Sclerotherapy using sclerosants (such as ethanol or polidocanol) can also be used for a bleeding Dieulafoy's lesion. A few studies have shown that successful control of a bleeding Dieulafoy's lesion could be achieved by local injection of polidocanol at four sites around the vessel and then into the vessel itself. . $^{240}$

\section{Thermal coagulation}

Thermal endoscopic hemostasis can be classified as either contact or noncontact. Bipolar electrocoagulation and heater probe coagulation are examples of contact thermocoagulation. The use of contact thermal methods alone has been criticized because of the possibility of inadequate coagulation of
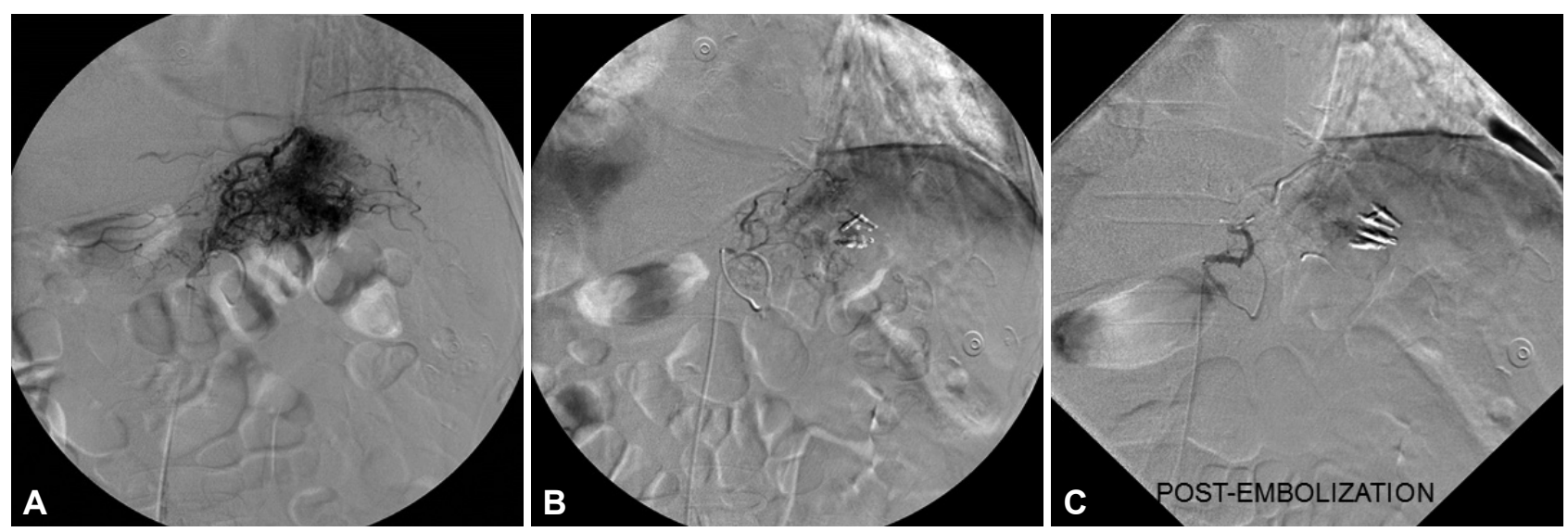

Fig. 2. Angiographic findings of Dieulafoy's lesions in the gastrointestinal tract. Angiographic intervention was performed after unsuccessful endoscopic treatment (hemostatic clip application) of a bleeding Dieulafoy's lesion on the upper body of the stomach. (A) There is an extravasation of contrast from a branch of the left gastric artery. (B) Gel-foam embolization was performed. (C) Extravasation of contrast was no longer seen on angiography. 
the lesion when covered by blood.$^{51}$ APC is a noncontact thermocoagulation technique that delivers high-frequency monopolar current through a conductive gas to the submucosa. ${ }^{52}$ This method has advantages over contact thermal methods, because it is relatively easy to use and reduces the risk of perforation by limiting the depth of tissue damage. ${ }^{53}$ One study reported that APC alone is a highly effective method for the treatment of an actively bleeding Dieulafoy's lesion. ${ }^{36}$

\section{Mechanical therapy}

Hemorrhage can also be controlled by mechanical methods such as endoscopic band ligation (EBL) or application of he-

Table 1. Results of Endoscopic Therapies for Dieulafoy's Lesions

\begin{tabular}{|c|c|c|c|c|c|c|c|}
\hline Study & Study design & Technique & Patient no. & $\begin{array}{c}\text { Initial } \\
\text { hemostasis }\end{array}$ & $\begin{array}{l}\text { Recurrent } \\
\text { bleeding }\end{array}$ & Surgery & $\begin{array}{c}\text { Bleeding } \\
\text { related deaths }\end{array}$ \\
\hline Asaki et al. $(1988)^{42}$ & Retrospective & Ethanol & 45 & $45(100)$ & $5(11)$ & $1(2)$ & 0 \\
\hline Stark et al. $(1992)^{7}$ & Retrospective & Epin+HP & 19 & $18(95)$ & $1(5)$ & $1(5)$ & 0 \\
\hline Baettig et al. $(1993)^{24}$ & Retrospective & Epin/Polidoc & 28 & $27(96)$ & $1(5)$ & $2(7)$ & 0 \\
\hline \multirow[t]{2}{*}{ Parra-Blanco et al. (1997) ${ }^{18}$} & Retrospective & $\mathrm{HP}$ & 6 & $4(67)$ & $1(17)$ & $1(17)$ & 0 \\
\hline & & Clip & 18 & $17(94.4)$ & $1(6)$ & 0 & 0 \\
\hline Norton et al. (1999) ${ }^{34}$ & Retrospective & $\mathrm{HP}$ & 85 & $82(97)$ & $8(9)$ & $3(4)$ & $4(5)$ \\
\hline \multirow[t]{2}{*}{ Chung et al. $(2000)^{39}$} & Prospective & Epin & 12 & $9(75)$ & $4(33)$ & $2(17)$ & 0 \\
\hline & & Clip/EBL & 12 & $11(92)$ & $1(8)$ & 0 & 0 \\
\hline Schmulewitz et al. $(2001)^{13}$ & Retrospective & Epin $+\mathrm{HP}$ & 40 & $36(90)$ & $1(3)$ & $3(8)$ & 0 \\
\hline Nikolaidis et al. $(2001)^{38}$ & Retrospective & $\mathrm{EBL}$ & 23 & $22(96)$ & $1(4)$ & $1(4)$ & 0 \\
\hline \multirow[t]{2}{*}{ Kasapidis et al. $(2002)^{4}$} & Retrospective & Epin+ethanol & 9 & $4(44.4)$ & $5(27)$ & $1(12.5)$ & 0 \\
\hline & & Epin+HP & 9 & $9(100)$ & 0 & 0 & 0 \\
\hline \multirow[t]{2}{*}{ Matsui et al. $(2002)^{43}$} & Prospective & Bipolar probe & 14 & $12(84)$ & $1(7)$ & 0 & 0 \\
\hline & & $\mathrm{EBL}$ & 13 & $13(100)$ & 0 & 0 & 0 \\
\hline \multirow[t]{2}{*}{ Mumtaz et al. $(2003)^{32}$} & Retrospective & Non-EBL & 9 & $9(100)$ & $1(11)$ & 0 & 0 \\
\hline & & EBL & 14 & $14(100)$ & 0 & 0 & 0 \\
\hline Yamaguchi et al. $(2003)^{40}$ & Prospective & Clip & 34 & $32(94)$ & $3(9)$ & 0 & 0 \\
\hline \multirow[t]{2}{*}{ Park et al. $(2003)^{33}$} & Prospective & Epin & 16 & $14(88)$ & $5(36)$ & $2(13)$ & 0 \\
\hline & & Clip & 16 & $15(94)$ & 0 & 0 & 0 \\
\hline \multirow[t]{2}{*}{ Park et al. $(2004)^{10}$} & Prospective & EBL & 13 & $13(100)$ & $1(8)$ & 0 & 0 \\
\hline & & Clip & 13 & $13(100)$ & $1(8)$ & 0 & 0 \\
\hline Romãozinho et al. $(2004)^{44}$ & Retrospective & Epin+ethanol & 69 & $63(91)$ & $13(19)$ & $11(16)$ & 0 \\
\hline \multirow[t]{2}{*}{ Cheng et al. $(2004)^{45}$} & Retrospective & Epin & 11 & $8(73)$ & $2(18)$ & $2(18)$ & $1(9)$ \\
\hline & & Epin $+\mathrm{HP}$ & 10 & $10(100)$ & 0 & 0 & 0 \\
\hline Walmsley et al. $(2005)^{46}$ & Retrospective & Epin $+\mathrm{HP}$ & 33 & $29(88)$ & $4(12)$ & $3(9)$ & $3(9)$ \\
\hline Sone et al. $(2005)^{11}$ & Retrospective & Clip+injection & 61 & $61(100)$ & $1(2)$ & 0 & 0 \\
\hline Ljubicic $(2006)^{47}$ & Retrospective & Clip & 21 & $20(95)$ & $2(10)$ & $1(5)$ & $1(5)$ \\
\hline Iacopini et al. $(2007)^{36}$ & Retrospective & $\mathrm{APC}$ & 23 & $23(100)$ & $1(4)$ & 0 & 0 \\
\hline Lim et al. $(2009)^{41}$ & Retrospective & Epin+clip & 44 & $39(89)$ & $7(18)$ & $2(4.5)$ & 0 \\
\hline \multirow[t]{2}{*}{ Alis et al. $(2009)^{35}$} & Prospective & Injection & 8 & $8(100)$ & $6(75)$ & $1(13)$ & - \\
\hline & & EBL & 10 & $10(100)$ & 0 & 0 & - \\
\hline Lara et al. $(2010)^{12}$ & Retrospective & Injection & 62 & $58(92)$ & $4(6)$ & $1(2)$ & $3(5)$ \\
\hline Dulic-Lakovic et al. $(2011)^{21}$ & Retrospective & APC/clip & 10 & $10(100)$ & $2(20)$ & $2(20)$ & 0 \\
\hline \multirow[t]{2}{*}{ Ahn et al. $(2012)^{37}$} & Retrospective & Clip & 34 & $34(100)$ & $5(15)$ & 0 & 0 \\
\hline & & $\mathrm{EBL}$ & 32 & $32(100)$ & $1(3)$ & 0 & 0 \\
\hline
\end{tabular}

Values are presented as number (\%).

Epin, 1:10,000 epinephrine solution; HP, heat probe; Polidoc, polidocanol; EBL, endoscopic band ligation; APC, argon plasma coagulation. 
moclips, both of which have been considered to be the first option in the management of Dieulafoy's lesions. ${ }^{14,54}$

\section{Hemostatic clipping}

One of the most widely used endoscopic mechanical therapies is hemoclipping (Fig. 3). It is suggested to be useful and more successful than injection therapy in achieving permanent hemostasis for bleeding Dieulafoy's lesions. ${ }^{33}$ However, it is difficult to apply a hemoclip when the angle of approach is tangential or when the lesion is located at the difficult sites (particularly, the gastric fundus, the lesser curvature of the stomach, or the posterior wall of the duodenal bulb) or when the lesion has a fibrotic ulcer base. In addition, prior incorrectly deployed hemoclips can hinder the accurate positioning of subsequent hemoclips. ${ }^{10,55}$ Therefore, it is important to apply the hemoclips accurately on Dieulafoy's lesions, particularly the first one. ${ }^{56}$ For this reason, endoscopic hemoclip application should be reserved for experienced endoscopists; nonetheless, it is a good therapy option for Dieulafoy's lesions. ${ }^{11,57}$

\section{Band ligation}

EBL is another mechanical hemostatic option (Fig. 4). The advantages of EBL are ease of use, accessibility to difficult sites (particularly, the esophagogastric junction and the posterior wall of the proximal body of the stomach), and low perforation risk. However, it also has limitations such as poor visual field, unfeasibility in fibrotic tissue, the time interval required to prepare the device, and the difficulty of re-intubation due to the presence of the band-ligating device itself. EBL is also associated with some complications such as delayed bleeding in the case of a residual vessel within a necrotic ulcer as well as perforation. ${ }^{10,37}$ Following the first use of EBL for Dieulafoy's lesion in 1994, ${ }^{58} \mathrm{EBL}$ has proven to be as effective as bipolar coagulation for Dieulafoy's lesions and has been found to be a simple, successful, effective, and inexpensive procedure. ${ }^{10,32,38,59}$

\section{Other endoscopic treatments}

\section{Over-the-scope clip}

An over-the-scope clip (OTSC) has been developed for the closure of small mural defects. ${ }^{60} \mathrm{~A}$ few studies have reported the use of OTSC for management of a Dieulafoy's lesion, ${ }^{61,62}$ and it may find potential application in routine endoscopic therapy of these lesions.
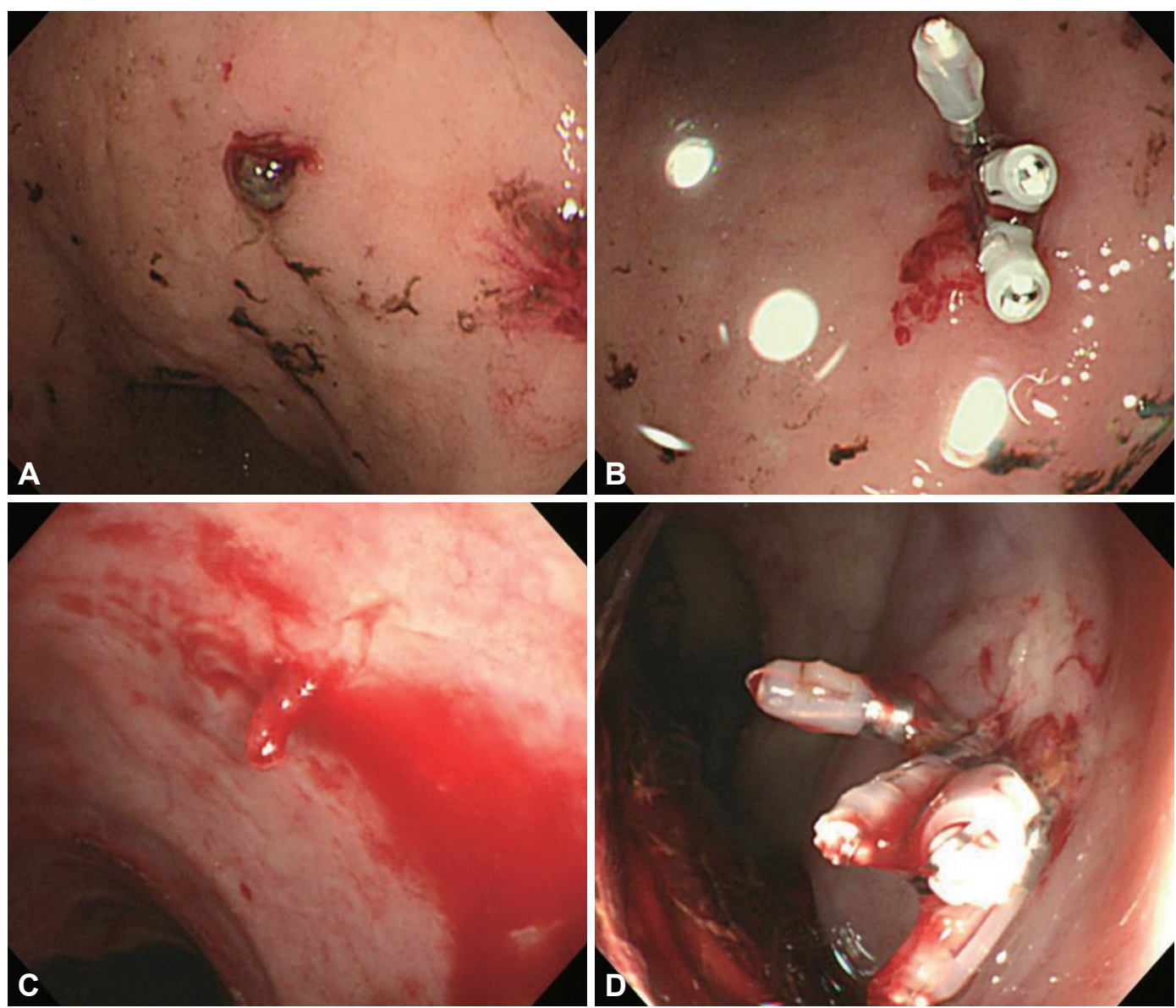

Fig. 3. Endoscopic hemostatic clip application to Dieulafoy's lesions in the stomach (A, B) and colon (C, D). 
EUS-guided treatment

EUS-guided treatment of the underlying vessel could be considered. EUS may help detection of the aberrant vessel in the submucosa, and it may also confirm ablation of a Dieulafoy's lesion after injection therapy or EBL by confirming absence of blood flow. ${ }^{14}$

\section{Which is the preferred procedure for bleeding dieulafoy's lesions?}

Each technique has both advantages and disadvantages related to the hemostatic mechanism involved, the technical procedure itself, and varying success rates (Table 2). ${ }^{39}$

\section{Monotherapy vs. combination therapy}

Combination endoscopic therapy is superior to monotherapy and consists of injection therapy followed by thermal or mechanical therapy, with permanent hemostasis achieved in 95\% of all cases (Fig. 5). ${ }^{14}$ A lower rate of bleeding recurrence has been described with the use of combined endoscopic treatment compared with monotherapy., ${ }^{9,14,63}$

\section{Mechanical therapy vs. other methods}

Theoretically, mechanical hemostasis leads to less damage to the surrounding tissue than other modalities, ${ }^{40}$ and several studies have shown that mechanical therapies including hemostatic clipping and EBL are more effective and successful in achieving hemostasis than other endoscopic methods, such as injection and thermal therapy. ${ }^{10,32,33,35,39,64}$ These reports suggest that mechanical therapy could be an appropriate first-line approach for the management of a Dieulafoy's lesions.

\section{Of the available mechanical therapies, which is preferred?}

One prospective, randomized trial reported equivalent hemostatic efficacy and clinical outcome of hemostatic clipping and EBL. ${ }^{10}$ Another study showed EBL can be used as an initial hemostatic method for bleeding Dieulafoy's lesions because of a favorable clinical outcome comparable with that of hemostatic clipping, as well as a shorter procedure time. ${ }^{37}$

\section{PROGNOSIS AND REBLEEDING}

Advances in endoscopic techniques have reduced mortality from GI bleeding in general and dramatically in patients with a Dieulafoy's lesion-from $80 \%$ to $8 \%$ - and the need for surgical intervention has been reduced. ${ }^{1}$ The risk of rebleeding from Dieulafoy's lesions is reported to be $9 \%$ to $40 \%$. The recur-
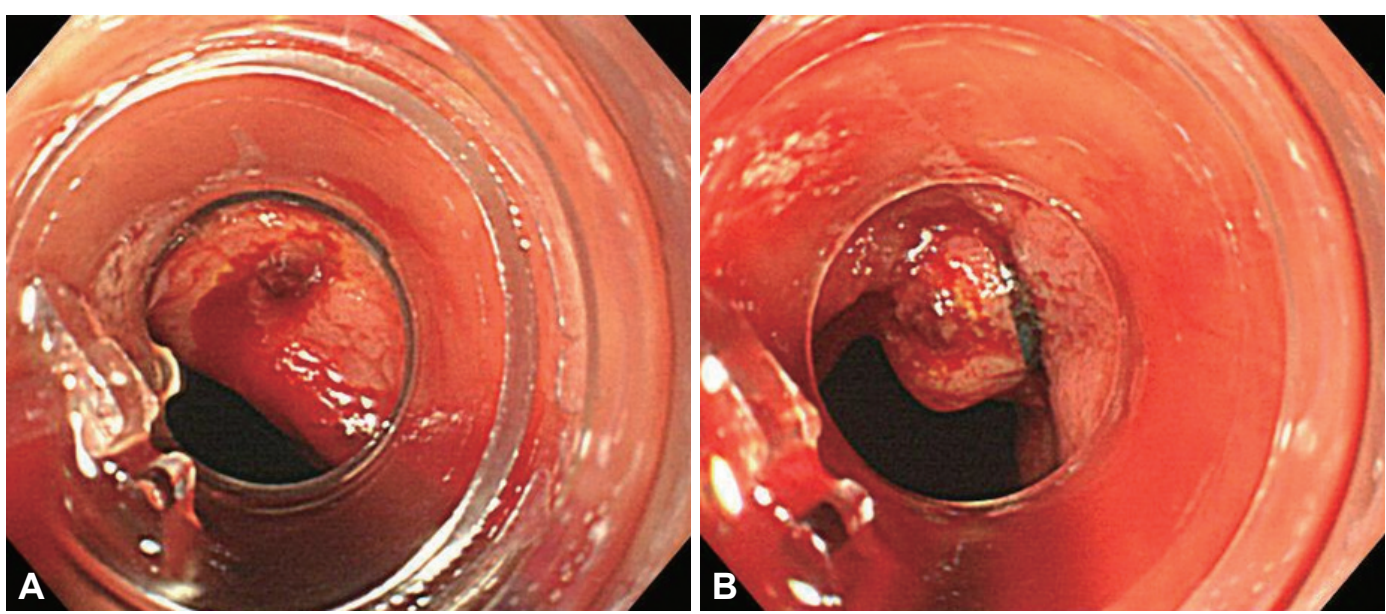

Fig. 4. Endoscopic band ligation to a Dieulafoy's lesion just below the gastroesophageal junction (A, B).

Table 2. Advantages and Disadvantages of Endoscopic Techniques for Dieulafoy's Lesions

\begin{tabular}{lll}
\hline & \multicolumn{1}{c}{ Advantages } & \multicolumn{1}{c}{ Disadvantages } \\
\hline Epinephrine injection & $\begin{array}{l}\text { Simple and inexpensive } \\
\text { Safe (avoids damage to the bowel wall) }\end{array}$ & High risk of rebleeding \\
Argon plasma coagulation & $\begin{array}{l}\text { Easy to use } \\
\text { Safe }\end{array}$ & $\begin{array}{c}\text { Possibility of only superficial coagulation (inaccessible } \\
\text { to larger, deeper vessels) }\end{array}$ \\
Clipping & Low risk of rebleeding & $\begin{array}{l}\text { Requires more experience } \\
\text { Difficulty in applying clips to specific sites }\end{array}$ \\
Band ligation & Easy to use & Poor visual field \\
& Accessible to difficult sites & Possibility of delayed bleeding or perforation \\
& Low risk of rebleeding & \\
\hline
\end{tabular}



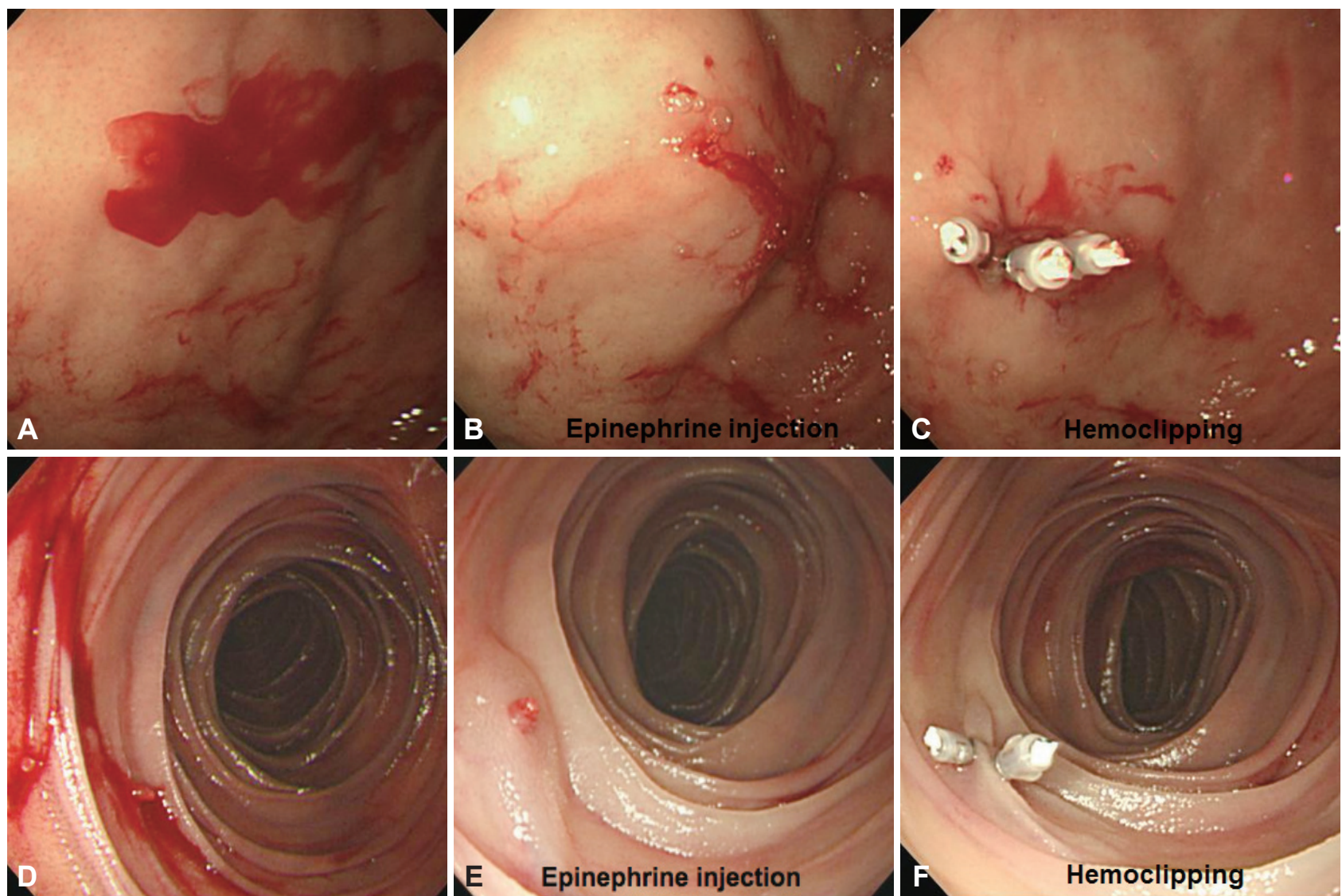

Fig. 5. Combination therapy consists of epinephrine injection therapy followed by hemostatic clipping of Dieulafoy's lesions in the stomach $(A-C)$ and the jejunum $(D-F)$.

rence of bleeding is higher in endoscopic monotherapy compared with combination therapy. ${ }^{914}$ In addition, several studies have identified risk factors of rebleeding such as the use of NSAIDs or anticoagulants, ${ }^{41}$ and the endoscopic findings of arterial (spurting) bleeding. ${ }^{41,63}$ It should be noted that the endoscopic methods of hemostasis are the preferred treatment in rebleeding from a Dieulafoy's lesion. ${ }^{65}$

\section{OTHER MANAGEMENT OPTIONS FOR DIEULAFOY'S LESION}

Endoscopic treatment is currently considered the first option for the management of Dieulafoy's lesions, whereas surgery or selective arterial embolization is advocated for cases with intractable bleeding or unsuccessful endoscopic therapy. ${ }^{3}$

\section{Angiography and embolization}

Angiography may also be used for both localization and therapy by gel-foam embolization of the bleeding vessel (Fig. 2). This treatment is an effective option if endoscopic therapy is unsuccessful. However, there is a potential risk of ischemia to the area supplied by the relevant artery following angiographic embolization. If the bleeding lesion is supplied by multiple collateral vessels, angiographic embolization may be an unsuitable choice of treatment because of the risk of the resultant ischemia. ${ }^{1}$

\section{Surgical treatment}

Surgery is the last option for patients with uncontrolled recurrent bleeding or an unidentified bleeding site. The current surgical mainstay treatment is local excision or wide wedge resection, even though the mortality in emergency surgery for acute GI bleeding is quite high. ${ }^{14}$

\section{CONCLUSIONS}

Dieulafoy's lesion is increasingly being identified as a cause of major GI bleeding. With advances in GI endoscopy, as both a diagnostic and therapeutic modality, overall mortality has decreased. Therefore, endoscopy should be the initial therapeutic approach in a bleeding Dieulafoy's lesion. There are several endoscopic therapeutic methods available; however, the best modality for management of a bleeding Dieulafoy's lesion has not been clearly demonstrated. Nevertheless, there is some evidence supporting better therapeutic efficacy of combination and mechanical therapy over other endoscopic 
therapies. Currently, surgical intervention is used only after failure of therapeutic endoscopic and angiographic interventions and it should be guided by preoperative localization.

\section{Conflicts of Interest}

The authors have no financial conflicts of interest.

\section{Acknowledgments}

This work was supported by a clinical research grant from the Pusan National University Hospital 2014.

\section{REFERENCES}

1. Baxter M, Aly EH. Dieulafoy's lesion: current trends in diagnosis and management. Ann R Coll Surg Engl 2010;92:548-554.

2. Amaro R, Petruff CA, Rogers AI. Rectal Dieulafoy's lesion: report of a case and review of the literature. Dis Colon Rectum 1999;42:1339-1341.

3. Veldhuyzen van Zanten SJ, Bartelsman JF, Schipper ME, Tytgat GN. Recurrent massive haematemesis from Dieulafoy vascular malformations: a review of 101 cases. Gut 1986;27:213-222.

4. Kasapidis P, Georgopoulos P, Delis V, Balatsos V, Konstantinidis A, Skandalis N. Endoscopic management and long-term follow-up of Dieulafoy's lesions in the upper GI tract. Gastrointest Endosc 2002;55:527-531.

5. Jain R, Chetty R. Dieulafoy disease of the colon. Arch Pathol Lab Med 2009;133:1865-1867.

6. Chaer RA, Helton WS. Dieulafoy's disease. J Am Coll Surg 2003;196: 290-296.

7. Stark ME, Gostout CJ, Balm RK. Clinical features and endoscopic management of Dieulafoy's disease. Gastrointest Endosc 1992;38:545-550.

8. Strong RW. Dieulafoy's disease: a distinct clinical entity. Aust N Z J Surg 1984;54:337-339.

9. Marangoni G, Cresswell AB, Faraj W, Shaikh H, Bowles MJ. An uncommon cause of life-threatening gastrointestinal bleeding: 2 synchronous Dieulafoy lesions. J Pediatr Surg 2009;44:441-443.

10. Park CH, Joo YE, Kim HS, Choi SK, Rew JS, Kim SJ. A prospective, randomized trial of endoscopic band ligation versus endoscopic hemoclip placement for bleeding gastric Dieulafoy's lesions. Endoscopy 2004;36:677-681.

11. Sone Y, Kumada T, Toyoda H, Hisanaga Y, Kiriyama S, Tanikawa M. Endoscopic management and follow up of Dieulafoy lesion in the upper gastrointestinal tract. Endoscopy 2005;37:449-453.

12. Lara LF, Sreenarasimhaiah J, Tang SJ, Afonso BB, Rockey DC. Dieulafoy lesions of the GI tract: localization and therapeutic outcomes. Dig Dis Sci 2010;55:3436-3441.

13. Schmulewitz N, Baillie J. Dieulafoy lesions: a review of 6 years of experience at a tertiary referral center. Am J Gastroenterol 2001;96:1688-1694.

14. Lee YT, Walmsley RS, Leong RW, Sung JJ. Dieulafoy's lesion. Gastrointest Endosc 2003;58:236-243.

15. Juler GL, Labitzke HG, Lamb R, Allen R. The pathogenesis of Dieulafoy's gastric erosion. Am J Gastroenterol 1984;79:195-200.

16. Morowitz MJ, Markowitz R, Kamath BM, von Allmen D. Dieulafoy's lesion and segmental dilatation of the small bowel: an uncommon cause of gastrointestinal bleeding. J Pediatr Surg 2004;39:1726-1728.

17. Fockens P, Tytgat GN. Dieulafoy's disease. Gastrointest Endosc Clin N Am 1996;6:739-752.

18. Parra-Blanco A, Takahashi H, Méndez Jerez PV, et al. Endoscopic management of Dieulafoy lesions of the stomach: a case study of 26 patients. Endoscopy 1997;29:834-839.

19. Alshumrani G, Almuaikeel M. Angiographic findings and endovascular embolization in Dieulafoy disease: a case report and literature review. Diagn Interv Radiol 2006;12:151-154.

20. al-Mishlab T, Amin AM, Ellul JP. Dieulafoy's lesion: an obscure cause of GI bleeding. J R Coll Surg Edinb 1999;44:222-225.

21. Dulic-Lakovic E, Dulic M, Hubner D, et al. Bleeding Dieulafoy lesions of the small bowel: a systematic study on the epidemiology and efficacy of enteroscopic treatment. Gastrointest Endosc 2011;74:573-580.

22. Yoshikumi Y, Mashima H, Suzuki J, et al. A case of rectal Dieulafoy's ulcer and successful endoscopic band ligation. Can J Gastroenterol 2006;20:287-290.

23. Firat O, Karaköse Y, Calişkan C, Makay O, Ozütemiz O, Korkut MA. Dieulafoy's lesion of the anal canal: report of a case. Turk J Gastroenterol 2007;18:265-267.

24. Baettig B, Haecki W, Lammer F, Jost R. Dieulafoy's disease: endoscopic treatment and follow up. Gut 1993;34:1418-1421.

25. Reilly HF 3rd, al-Kawas FH. Dieulafoy's lesion. Diagnosis and management. Dig Dis Sci 1991;36:1702-1707.

26. Ibrarullah M, Wagholikar GD. Dieulafoy's lesion of duodenum: a case report. BMC Gastroenterol 2003;3:2.

27. Carvalho R, Almeida N, Ferreira M, et al. An unusual endoscopic image of a submucosal angiodysplasia. Case Rep Gastrointest Med 2012; 2012:186065.

28. Fockens P, Meenan J, van Dullemen HM, Bolwerk CJ, Tytgat GN. Dieulafoy's disease: endosonographic detection and endosonographyguided treatment. Gastrointest Endosc 1996;44:437-442.

29. Sai Prasad TR, Lim KH, Lim KH, Yap TL. Bleeding jejunal Dieulafoy pseudopolyp: capsule endoscopic detection and laparoscopic-assisted resection. J Laparoendosc Adv Surg Tech A 2007;17:509-512.

30. Lai LH. Obscure GI bleeding: is capsule endoscopy sufficient? Gastrointest Endosc 2008;68:1128-1130.

31. Goldenberg SP, DeLuca VA Jr, Marignani P. Endoscopic treatment of Dieulafoy's lesion of the duodenum. Am J Gastroenterol 1990;85:452454.

32. Mumtaz R, Shaukat M, Ramirez FC. Outcomes of endoscopic treatment of gastroduodenal Dieulafoy's lesion with rubber band ligation and thermal/injection therapy. J Clin Gastroenterol 2003;36:310-314.

33. Park CH, Sohn YH, Lee WS, et al. The usefulness of endoscopic hemoclipping for bleeding Dieulafoy lesions. Endoscopy 2003;35:388-392.

34. Norton ID, Petersen BT, Sorbi D, Balm RK, Alexander GL, Gostout CJ. Management and long-term prognosis of Dieulafoy lesion. Gastrointest Endosc 1999;50:762-767.

35. Alis $\mathrm{H}$, Oner OZ, Kalayci MU, et al. Is endoscopic band ligation superior to injection therapy for Dieulafoy lesion? Surg Endosc 2009;23: 1465-1469.

36. Iacopini F, Petruzziello L, Marchese M, et al. Hemostasis of Dieulafoy's lesions by argon plasma coagulation (with video). Gastrointest Endosc 2007;66:20-26.

37. Ahn DW, Lee SH, Park YS, et al. Hemostatic efficacy and clinical outcome of endoscopic treatment of Dieulafoy's lesions: comparison of endoscopic hemoclip placement and endoscopic band ligation. Gastrointest Endosc 2012;75:32-38.

38. Nikolaidis N, Zezos P, Giouleme O, et al. Endoscopic band ligation of Dieulafoy-like lesions in the upper gastrointestinal tract. Endoscopy 2001;33:754-760.

39. Chung IK, Kim EJ, Lee MS, et al. Bleeding Dieulafoy's lesions and the choice of endoscopic method: comparing the hemostatic efficacy of mechanical and injection methods. Gastrointest Endosc 2000;52:721-724.

40. Yamaguchi Y, Yamato T, Katsumi N, et al. Short-term and long-term benefits of endoscopic hemoclip application for Dieulafoy's lesion in the upper GI tract. Gastrointest Endosc 2003;57:653-656.

41. Lim W, Kim TO, Park SB, et al. Endoscopic treatment of dieulafoy lesions and risk factors for rebleeding. Korean J Intern Med 2009;24:318322.

42. Asaki S, Sato H, Nishimura T, et al. Endoscopic diagnosis and treatment of Dieulafoy's ulcer. Tohoku J Exp Med 1988;154:135-141.

43. Matsui S, Kamisako T, Kudo M, Inoue R. Endoscopic band ligation for control of nonvariceal upper GI hemorrhage: comparison with bipolar electrocoagulation. Gastrointest Endosc 2002;55:214-218.

44. Romãozinho JM, Pontes JM, Lérias C, Ferreira M, Freitas D. Dieulafoy's lesion: management and long-term outcome. Endoscopy 2004;36: 
416-420.

45. Cheng CL, Liu NJ, Lee CS, et al. Endoscopic management of Dieulafoy lesions in acute nonvariceal upper gastrointestinal bleeding. Dig Dis Sci 2004;49:1139-1144.

46. Walmsley RS, Lee YT, Sung JJ. Dieulafoy's lesion: a case series study. World J Gastroenterol 2005;11:3574-3577.

47. Ljubicic N. Efficacy of endoscopic clipping and long-term follow-up of bleeding Dieulafoy's lesions in the upper gastrointestinal tract. Hepatogastroenterology 2006;53:224-227.

48. De Palma GD, Patrone F, Rega M, Simeoli I, Masone S, Persico G. Actively bleeding Dieulafoy's lesion of the small bowel identified by capsule endoscopy and treated by push enteroscopy. World J Gastroenterol 2006;12:3936-3937.

49. Pointner R, Schwab G, Königsrainer A, Dietze O. Endoscopic treatment of Dieulafoy's disease. Gastroenterology 1988;94:563-566.

50. Skok P. Endoscopic hemostasis in exulceratio simplex-Dieulafoy's disease hemorrhage: a review of 25 cases. Endoscopy 1998;30:590-594.

51. Lin HJ, Tsai YT, Lee SD, et al. A prospectively randomized trial of heat probe thermocoagulation versus pure alcohol injection in nonvariceal peptic ulcer hemorrhage. Am J Gastroenterol 1988;83:283-286.

52. Shudo R, Yazaki Y, Sakurai S, Uenishi H, Yamada H, Sugawara K. Diffuse antral vascular ectasia: EUS after argon plasma coagulation. Gastrointest Endosc 2001;54:623.

53. Canard JM, Vedrenne B. Clinical application of argon plasma coagulation in gastrointestinal endoscopy: has the time come to replace the laser? Endoscopy 2001;33:353-357.

54. Valera JM, Pino RQ, Poniachik J, et al. Endoscopic band ligation of bleeding dieulafoy lesions: the best therapeutic strategy. Endoscopy 2006;38:193-194.

55. Kim KB, Yoon SM, Youn SJ. Endoscopy for nonvariceal upper gastrointestinal bleeding. Clin Endosc 2014;47:315-319.
56. Gimeno-García AZ, Parra-Blanco A, Nicolás-Pérez D, Ortega Sánchez JA, Medina C, Quintero E. Management of colonic Dieulafoy lesions with endoscopic mechanical techniques: report of two cases. Dis Colon Rectum 2004;47:1539-1543.

57. Lee BI, Kim BW, Choi H, et al. Hemoclip placement through a forwardviewing endoscope for a Dieulafoy-like lesion in a duodenal diverticulum. Gastrointest Endosc 2003;58:813-814.

58. Brown GR, Harford WV, Jones WF. Endoscopic band ligation of an actively bleeding Dieulafoy lesion. Gastrointest Endosc 1994;40:501-503.

59. Xavier S. Band ligation of Dieulafoy lesions. Indian J Gastroenterol 2005; 24:114-115.

60. Kirschniak A, Kratt T, Stüker D, Braun A, Schurr MO, Königsrainer A. A new endoscopic over-the-scope clip system for treatment of lesions and bleeding in the GI tract: first clinical experiences. Gastrointest Endosc 2007;66:162-167.

61. Gomez V, Kyanam Kabir Baig KR, Lukens FJ, Woodward T. Novel treatment of a gastric Dieulafoy lesion with an over-the-scope clip. Endoscopy 2013;45(Suppl 2 UCTN):E71.

62. Mangiavillano B, Arena M, Morandi E, Viaggi P, Masci E. Successful treatment with an over-the-scope clip of Dieulafoy's gastric lesion resistant to conventional endoscopic treatment. Endoscopy 2012;44(Suppl 2 UCTN):E387.

63. Jamanca-Poma Y, Velasco-Guardado A, Piñero-Pérez C, et al. Prognostic factors for recurrence of gastrointestinal bleeding due to Dieulafoy's lesion. World J Gastroenterol 2012;18:5734-5738.

64. Katsinelos P, Paroutoglou G, Mimidis K, et al. Endoscopic treatment and follow-up of gastrointestinal Dieulafoy's lesions. World J Gastroenterol 2005; 11:6022-6026.

65. Pathan NF, El-Fanek H. A 70-year-old man with episodes of upper gastrointestinal bleeding. Dieulafoy lesion/malformation. Arch Pathol Lab Med 2006;130:e27-e29. 